\title{
O PROCESSO CONSTITUCIONAL COMO ELEMENTO ESSENCIAL PARA A CONCRETIZAÇÃO DA DEMOCRACIA DO DIREITO IBERO-AMERICANO
}

\section{Gabriela Oliveira Freitas}

Doutoranda, Mestre e Especialista em Direito Processual pela PUC Minas. Coordenadora-Adjunta e Pesquisadora do IMDP - Instituto Mineiro de Direito Processual. Editora Chefe das Revistas Cadernos Jurídicos do IMDP e Revista Jurídica IMDP. Assistente Judiciária do Tribunal de Justiça do Estado de Minas Gerais (TJMG). Professora de Direito Processual da FUNCESI - Fundação Comunitária de Ensino Superior de Itabira e da Anhanguera Educacional. E-mail: gabriela.freitas@funcesi.br. Currículo Lattes: http://lattes.cnpq.br/4971454368506778.

\section{Sérgio Henriques Zandona Freitas}

Doutor, Mestre e Especialista em Direito Processual pela PUC Minas. Professor de Direito Processual e Metodologia da Pesquisa Jurídica na UNIVERSIDADE FUMEC. Coordenador do Núcleo de TCC e Supervisor do NPJ-REVISTA da UNIVERSIDADE FUMEC. Associado fundador e Coordenador Geral do Instituto Mineiro de Direito Processual (IMDP). Assessor Judiciário no Tribunal de Justiça do Estado de Minas Gerais (TJMG). E-mail: sergiohzf@fumec.br. Currículo Lattes: http:// lattes.cnpq.br/2720114652322968.

\section{Resumo}

O presente artigo científico aborda a mudança na concepçáo do processo e, por consequência, da atividade jurisdicional, a partir da instituição do Estado Democrático de Direito em diversos países europeus e da América Latina, ocorrida após a queda dos regimes totalitários. A partir de tal análise, demonstra-se como essa revisitaçáo do conceito de processo, tornou-o essencial para a concretização da democracia, por se tratar de um mecanismo de inclusão e participação popular contramajoritário, permitindo a discussão sobre temas que envolvem as minorias, normalmente excluídas dos procedimentos decisórios do Estado. Para o presente estudo, utilizou-se a pesquisa bibliográfica e o método dedutivo, partindo-se de uma perspectiva macro para uma concepção micro analítica acerca do tema ora em estudo e, por fim, como procedimento técnico a análise temática, teórica e interpretativa, buscando sugestão para a solução da questão destacada.

\section{Palavras-chave}

Democracia; Processo Constitucional; Direitos Fundamentais. 


\section{Resumen}

Este artículo científico aborda el cambio en el concepto del proceso y por lo tanto de la actividad judicial a partir de la institución del Estado Democrático de Derecho en varios países europeos y de América Latina, que tuvo lugar después de la caída de los regímenes totalitarios. A partir de este análisis, se muestra cómo esta revisitación del proceso de concepción, hace que sea esencial para la realización de la democracia, ya que es un mecanismo de inclusión y participación popular, contramajoritário, lo que permite la discusión de las cuestiones relativas a las minorías, generalmente excluidos de los procedimientos de toma de decisiones del Estado. Para el presente estudio, hemos utilizado la literatura y el método deductivo, a partir de una perspectiva macro para vista analítico micro sobre el tema objeto de estudio y, por último, como un procedimiento técnico para el análisis temático, teórico e interpretativo, buscando sugerencia para resolver la cuestión pendiente.

\section{Palabras clave}

Democracia; Proceso constitucional; Derechos Fundamentales.

\section{Introdução}

A Ibero-América representa uma região geográfica composta por três países da Península Ibérica (Portugal, Espanha e Andorra) e os países da América Latina hispanófona e lusófona, que integram a Comunidade Ibero-Americana de Naçóes, com afinidades linguística, histórica, cultural e jurídica. Assim, consideradas as referidas afinidades, diversos países componentes da Comunidade Ibero-Americana de Naçôes passaram por um processo semelhante de queda de regimes totalitários, seguidos da promulgação de uma nova Constituição, que instituiu, inaugurando ou reinaugurando, o Estado Democrático de Direito.

A instituição da democracia teve por objetivo a retirada da autoridade do Estado, transferindo o poder para o povo, o que se dá não só pelo direito ao voto, mas também pela possibilidade de fiscalizaçáo dos atos do Estado pelo povo e pelo direito de participar ativamente na construção dos provimentos estatais, sejam eles emanados pelo Executivo, Legislativo ou Judiciário.

Assim, com a queda do Estado Social e instituição do Estado Democrático de Direito, tornou-se necessário revisitar alguns institutos jurídicos, dentre eles o Processo, o qual ganhou uma nova perspectiva. Essa mudança tão significativa inviabiliza uma análise do direito e, por conseguinte, da atividade jurisdicional sob outra perspectiva que náo seja a democrática. Isso porque os textos constitucionais incluíram diversas garantias processuais dentre o rol de direitos e garantias fundamentais. 
Os princípios básicos do Direito Processual passaram a ser tratados como parte do Direito Constitucional, o que modifica por completo o conceito de processo, que não pode mais ser compreendido como uma relação jurídica entre as partes, na qual um excesso de poderes, sejam eles instrutórios ou decisórios, é conferido ao órgão julgador, diante da justificativa de busca pela "justiça" e "paz social", dentre outros escopos metajurídicos. Tal concepção do processo seria típica de um Estado Social.

Nessa nova conjuntura, o processo passa a ser compreendido como um procedimento constitucionalizado realizado em contraditório entre as partes, com o objetivo principal de garantir o efetivo exercício dos direitos fundamentais, ou seja, a partir do marco teórico da Teoria Constitucionalista do Processo, sistematizada por Hector Fix-Zamudio.

Diante de tais consideraçóes, pretende-se analisar, no primeiro capítulo, as garantias processuais previstas nos textos constitucionais pós-regimes totalitários, que aproximam o processo do texto constitucional, e também estruturam o procedimento sobre bases democráticas ibero-americanas.

Em seguida, serão apresentadas algumas consideraçóes sobre a compreensão do que seja processo na matriz disciplinar do Estado Democrático de Direito, buscando esclarecer como ocorre a democratização do processo.

Por fim, analisar-se-á como essa nova concepção de processo faz com que este instituto seja essencial para a concretização da democracia no direito ibero-americano, abordando sua perspectiva contramajoritária, no sentido de permitir a participação popular daqueles que não conseguem se manifestar nas decisóes tomadas pela maioria.

\section{As Garantias Processuais nas Constituições Europeias e Latino America- nas}

Diversos textos constitucionais preveem a instituição de um Estado Democrático de Direito. Todavia, não basta a mera previsão no texto da Constituição, sendo necessário que esse mesmo texto, assim como o resto do ordenamento jurídico, institua mecanismos para o pleno e efetivo exercício da cidadania ${ }^{1}$.

Como já mencionado, a democracia não pode se limitar à vontade da maioria, mas deve permitir a inclusão de todos, com suas individualidades. Isto significa que a democracia deve estar diretamente vinculada à "prerrogativa de autoinclusão da Cidadania”, garantindo que "cada pessoa promova sua própria inserção na ordem jurídica” (GRESTA, 2014, p. 10).

1 Compreende-se cidadania como "deliberado vínculo jurídico-político-constitucional que qualifica o indivíduo como condutor de decisôes, construtor e reconstrutor do ordenamento jurídico da sociedade política a que se filiou" (LEAL, 2002, p. 150-151). 
Assim, as Constituiçóes analisadas neste trabalho caracterizam pela verdadeira pretensão de construir o Estado Democrático de Direito, trazendo não só direitos fundamentais para todos, como exemplo para as demais, mas também mecanismos de garantia desses direitos.

Induvidoso que a Constituição deve não somente tutelar determinados direitos humanos, mas como também inserir em seu texto meios de garantias para que esses direitos possam ser amplamente exercidos, ou seja, a positivação dos direitos humanos é insuficiente para assegurar "a efetividade do livre exercício de tais direitos" (BARACHO, 2006, p. 53), exigindo-se que o ordenamento jurídico também crie garantias que os tornem eficazes.

No mesmo sentido, Ronaldo Brêtas de Carvalho Dias afirma que "de nada adiantaria um extenso rol de direitos fundamentais, se mecanismos que assegurassem sua concretização também não fossem selecionados e incluídos no texto constitucional” (BRÊTAS, 2010, p. 72).

Assim, conclui-se, conforme o ensinamento de José Cirilo Vargas, que a mera previsão e proclamação dos direitos é insuficiente, vez que é preciso "dar os meios para exercê-los, para desfrutá-los", de modo a "afastar a ideia de mero complexo de princípios filosóficos e generosos, sem eficácia executória” (VARGAS, 1992, p. 50).

As garantias constitucionais passam a ter grande relevância no estudo do processo, tendo em vista que várias dessas garantias, apesar de previstas no texto constitucional, possuem natureza processual, motivo pelo qual, no Estado Democrático de Direito, torna-se inviável desvincular o processo da Constituição.

Neste contexto, há duzentos anos, era aprovada a Constituição Espanhola de 1812 ou La Pepa, também conhecida como Constituição de Cádiz, em 18 de Março de 1812, pelas Cortes Gerais Extraordinárias reunidas na cidade de Cádiz, Espanha. Considerada a primeira constituição aprovada entre os países ibero-americanos, com características revolucionárias para a época e princípios consagradores do Estado de Direito e a democracia, influenciou profundamente o desenvolvimento do constitucionalismo espanhol, português e latino-americano, deixando um legado de inclusão política e social. A Constituição Espanhola de 1812 foi antecedida apenas pela Constituição Corsa de 1755 (a primeira efetivamente democrática), pela Constituição dos Estados Unidos da América (1787) e pela Constituição Francesa de 1791. (ESPANHA, 1912).

No Brasil, este marco constitucional apenas foi efetivamente atingido em 1988, com a promulgação da atual Constituição da República, findando um longo período ditatorial. O novo texto constitucional, em seu artigo $1^{\circ}$, reconhece o Brasil como um Estado Democrático de Direito, superando os antigos modelos de Estado, Social e Liberal, e modificando não só os limites da intervenção do Estado na esfera privada, mas também 
possibilitando que a atuação do Estado se tornasse a representação da vontade popular. (BRASIL, 1988).

No caso do Brasil, apesar de desde a primeira Constituição da República, promulgada em 1891, ter expressa previsão de que o texto constitucional tinha por objetivo a organização de um "regime livre e democrático", é certo que somente com a Constituição de 1988 foram criados mecanismos para efetivar tal promessa democrática, tendo existido, até então, um verdadeiro Estado Social, com um excesso de poderes do Estado e pouca, ou quase nenhuma, participação popular.

O mesmo se verifica na Constituição de Portugal, datada de 1974. Além de deixar claro em seu preâmbulo, a restituição aos cidadãos portugueses dos direitos e liberdades fundamentais, em razão da derrubada de um regime fascista, a Constituição Portuguesa inclui em seu texto garantias processuais como o contraditório e a ampla defesa (art. 32), o dever de fundamentar as decisóes judiciais (art. 205) e o amplo acesso à jurisdição e a razoável duração do processo (art. 20). (PORTUGAL, 1974).

No mesmo sentido, a Constituição italiana de 1947, aqui incluída a título exemplificativo eis que não componente da Comunidade Ibero-Americana de Naçôes, trouxe uma seção específica para a regulamentação da atividade jurisdicional, iniciando-se com a previsão da atuação mediante observância do devido processo legal ("giusto processo reglato dalla legge" - art. 111), seguindo, no mesmo artigo, com a previsão das demais garantias essenciais ao processo democrático. Dispóe a Constituição que "cada processo se desenvolve pelo debate entre as partes, em condiçôes de igualdade, perante tribunal independente e imparcial. A lei prevê a duração razoável.”2 (ITÁLIA, 1974).

A abordagem das garantias processuais como garantias fundamentais também se encontra na Constituição da Espanha de 1978, que prevê o acesso à jurisdição como direito fundamental, tutelado pela ampla defesa, dispondo que "todas as pessoas têm direito a proteção efetiva dos juízes e tribunais no exercício dos seus direitos e interesses legítimos, sem que, em qualquer caso, não haja defesa”’. (ESPANHA, 1978).

O mesmo dispositivo ainda prevê:

Além disso, todos têm direito a um juiz ordinário predeterminado por lei, a defesa e a assistência por um defensor, a ser informado das acusaçôes contra eles, a um julgamento público, sem dilaçốes indevidas e com plenas garantias, a utilização de todos os meios de prova relevantes para a

2 No original: "Ogni processo si svolge nel contraddittorio tra le parti, in condizioni di parità, davanti a giudice terzo e imparziale. La legge ne assicura la ragionevole durata”.

3 No original: "Todas las personas tienen derecho a obtener la tutela efectiva de los jueces y tribunales en el ejercicio de sus derechos e intereses legítimos, sin que, en ningún caso, pueda producirse indefensión." 
sua defesa, não se incriminar, não confessar-se culpado e a presunção de inocência. ${ }^{4}$ (ESPANHA, 1978).

Cabe aqui aclarar, interessante o posicionamento de Lenio Luiz Streck sobre a utilização da hermenêutica jurídica para intermediar o texto da lei e seu sentido. Para tanto:

na era das Constituiçóes compromissórias e sociais, uma hermenêutica jurídica capaz de intermediar a tensão inexorável entre o texto e o sentido do texto não pode continuar a ser entendida como uma teoria ornamental do direito, que sirva tâo somente para colocar 'capas de sentido' aos textos jurídicos. No interior da virtuosidade do círculo hermenêutico, o compreender não ocorre por dedução ou subsunção. Conseqüentemente, o método (ou o 'procedimento discursivo') sempre chega tarde, porque pressupor saberes teóricos (discursos de fundamentação) separados da 'realidade'. Antes de argumentar, o intérprete já compreendeu. $\mathrm{O}$ uso da linguagem não é arbitrário, isto é, 'a linguagem não depende de quem a usa' (Gadamer). A compreensão antecede qualquer argumentação, porque lhe é condição de possibilidade. Portanto, é equivocado afirmar, v.g., que o juiz primeiro decide e só depois fundamenta (justifica). Na verdade, ele só decide porque já encontrou, na antecipação de sentido, o fundamento. Mas somente é possível compreender isso a partir da admissão da tese de que a linguagem não é um mero instrumento ou uma 'terceira coisa' que se interpóe entre um sujeito (cognoscente) e um objeto (cognoscível). Numa palavra: o 'abismo gnosiológico' que 'separa' o homem das coisas e da compreensão acerca de como elas são não depende - no plano da hermenêutica jurídicofilosófica — de pontes que venham a ser construídas — paradoxalmente - depois que a travessia (antecipação de sentido) já tenha sido feita. (STRECK, 2006, p. 286).

Como exemplo, vale ainda mencionar a Constituição de Andorra de 1993, que traz as garantias fundamentais do processo em seu art. $10^{5}$, que também se encontram previstas

4 No original: "Asimismo, todos tienen derecho al Juez ordinario predeterminado por la ley, a la defensa y a la asistencia de letrado, a ser informados de la acusación formulada contra ellos, a un proceso público sin dilaciones indebidas y con todas las garantías, a utilizar los medios de prueba pertinentes para su defensa, a no declarar contra sí mismos, a no confesarse culpables y a la presunción de inocencia."

5 No original: "Article 10

1. Es reconeix el dret a la jurisdicció, a obtenir d'aquesta una decisió fonamentada en Dret, i a un procés degut, substanciat per un tribunal imparcial predeterminat per la llei.

2.Es garanteix a tothom el dret a la defensa i a l'assistència tècnica d'un lletrat, a un judici de durada raonable, a la presumpció d'innocència, a ésser informat de l'acusació, a no confessar-se culpable, a no declarar en contra d'ell mateix i, en els processos penals, al recurs.

3.La llei regularà els supòsits en què, per garantir el principi d'igualtat, la justícia ha d'ésser gratuïta." (ANDORRA, 1993). 
no art. 19 da Constituição do Chile de $1980^{6}$, no art. 139 da Constituição Peruana de $1993^{7}$ e no art. 29 da Constituição da Colômbia de $1991^{8}$.

Percebe-se que a inclusão no texto constitucional de diversas garantias processuais, que pretendem a efetividade dos direitos fundamentais, aproxima o processo da Constituição, tornando, ainda, o texto constitucional indispensável para o devido processo, situação esta que torna clara a denominação "modelo constitucional de processo". (BARACHO, 1984).

\section{O Processo no Estado Democrático de Direito}

Os textos constitucionais analisados no tópico anterior preveem a instauração do Estado Democrático de Direito, o que, em resumo, significa que o Estado contemporâneo fundamenta-se no exercício do poder pelo povo e limitação deste poder pelas normas do ordenamento jurídico, superando as noções de Estado Social e Estado Liberal. Portanto, entende-se por Estado Democrático de Direito aquele submetido às "normas do direito e estruturado por leis, sobretudo a lei constitucional", em que se estabelece uma "estreita conexão interna entre dois grandes princípios jurídicos, democracia e Estado de Direito" (BRÊTAS, 2010, p. 54).

6 No original: "La ley arbitrará los medios para otorgar asesoramiento y defensa jurídica a quienes no puedan procurárselos por sí mismos. La ley señalará los casos y establecerá la forma en que las personas naturales víctimas de delitos dispondrán de asesoría y defensa jurídica gratuitas, a efecto de ejercer la acción penal reconocida por esta Constitución y las leyes. Toda persona imputada de delito tiene derecho irrenunciable a ser asistida por un abogado defensor proporcionado por el Estado si no nombrare uno en la oportunidad establecida por la ley. Nadie podrá ser juzgado por comisiones especiales, sino por el tribunal que señalare la ley y que se hallare establecido por ésta con anterioridad a la perpetración del hecho. Toda sentencia de un órgano que ejerza jurisdicción debe fundarse en un proceso previo legalmente tramitado.Corresponderá al legislador establecer siempre las garantías de un procedimiento y una investigación racionales y justos." (CHILE, 1980).

7 O texto da Constituição do Peru de 1993 estabelece em seu art. 139 os princípios e direitos fundamentais da função jurisdicional, incluindo "la observancia del debido proceso y la tutela jurisdiccional", "La motivación escrita de las resoluciones judiciales en todas las instancias, excepto los decretos de mero trámite, con mención expresa de la ley aplicable y de los fundamentos de hecho en que se sustentan" e "El principio del derecho de toda persona de formular análisis y críticas de las resoluciones y sentencias judiciales, con las limitaciones de ley" (PERU, 1993).

8 No original: "El debido proceso se aplicará a toda clase de actuaciones judiciales y administrativas. Nadie podrá ser juzgado sino conforme a leyes preexistentes al acto que se le imputa, ante juez o tribunal competente y con observancia de la plenitud de las formas propias de cada juicio. En materia penal, la ley permisiva o favorable, aun cuando sea posterior, se aplicará de preferencia a la restrictiva o desfavorable. Toda persona se presume inocente mientras no se la haya declarado judicialmente culpable. Quien sea sindicado tiene derecho a la defensa y a la asistencia de un abogado escogido por él, o de oficio, durante la investigación y el juzgamiento; a un debido proceso público sin dilaciones injustificadas; a presentar pruebas y a controvertir las que se alleguen en su contra; a impugnar la sentencia condenatoria, y a no ser juzgado dos veces por el mismo hecho. Es nula, de pleno derecho, la prueba obtenida con violación del debido proceso." (COLÔMBIA, 1991). 
Ronaldo Brêtas de Carvalho Dias afirma que o Estado Democrático de Direito representa uma fusão entre o Estado de Direito e o princípio democrático e acrescenta que:

[...] essa fusão permite criar um sistema constitucional marcado de forma preponderante pela associação do poder político legitimado do povo (democracia) com a limitação do poder estatal pelas normas constitucionais e infraconstitucionais que integram seu ordenamento jurídico (Estado de Direito), sobretudo aquelas pertinentes aos direitos fundamentais. (BRÊTAS, 2010, p. 147).

No que se refere ao princípio democrático, deve-se observar que democracia remete, primariamente, à ideia "governo do povo". Ou seja: democracia significa permitir a participação do povo, conferindo legitimidade à atuação do Estado nas esferas legislativa, administrativa e judicial, nos termos dispostos no artigo $1^{\circ}$, parágrafo único, da Constituição da República do Brasil de 1988, segundo o qual "todo o poder emana do povo, que o exerce por meio de representantes eleitos ou diretamente". (BRASIL, 1988).

Buscando conceituar democracia, Simone Goyard-Fabre afirma que esta:

[...] define a forma de um regime que, fundando a autoridade do governo no povo, garante a presença dos governados ao exercício do poder. Por outro lado, transporta e transpóe para a esfera política o caráter conflituoso das paixóes humanas, de forma tal que, no mesmo movimento que suscita a esperança da liberdade e da igualdade, faz pesar sobre a Cidade as ameaças da desrazão que o desejo insaciável do povo introduz na razão. (GOYARD-FABRE, 2003, p. 13).

Assim, nessa matriz disciplinar, o poder é exercido em razão da vontade soberana do povo, que, por meio de uma série de direitos e garantias consagrados no ordenamento jurídico, também "possui direito de fiscalizar as formas de manifestação e aplicação de tal poder" (MADEIRA, 2009, p. 22), o que garante a legitimação democrática da atuação do Estado.

É o que assevera Ronaldo Brêtas:

Tudo isso significa permanente sujeição do Estado Brasileiro ao ordenamento jurídico vigente, integrado por normas de direito (regras e princípios jurídicos), emanadas da vontade do povo, que se manifesta por meio dos seus representantes eletivos ou diretamente, por meio do plebiscito, do referendo e da iniciativa popular, motivo da menção explícita da Constituição brasileira ao princípio da reserva legal (ou princípio da prevalência da lei), como garantia fundamental das pessoas (artigo $5^{\circ}$, II,), e ao princípio da legalidade, estruturante do Estado de Direito brasileiro (artigo 37). (BRÊTAS, 2006a, p. 156). 
Do princípio democrático ainda resulta, no âmbito jurisdicional, o dever do Estado e o direito do jurisdicionado de buscar uma resposta às suas pretensóes, com a devida fundamentação, mediante a garantia de ampla participação na construção das decisóes, observado, assim, o devido processo legal.

Em razão da consagração jurídico-constitucional dessa nova principiologia, o processo deve ser analisado sob uma perspectiva democrática e, por isso, é necessário romper com as teorias do processo que permitem a concepção da atividade jurisdicional como um poder do Estado, a fim de compreendê-la como um direito fundamental. Esse rompimento deve ser estabelecido, principalmente, com a Teoria do Processo como Relação Jurídica, sistematizada por Büllow, segundo a qual o processo é uma relação jurídica entre autor, réu e juiz. Tal teoria foi trazida ao Brasil por Enrico Tulio Liebman, influenciando Alfredo Buzaid na elaboração do Código de Processo Civil de 1973 e sendo acompanhada pela intitulada Escola Paulista/Instrumentalista de Processo. (BRASIL, 1973a)

O Código de Processo Civil brasileiro de 1973 sofreu, ao longo dos quarenta anos de vigência, mais de sessenta e seis leis modificadoras de seu conteúdo, sendo seis na década de 70 , onze na década de 80 , vinte e duas na década de 90 , demonstrando forte produção legislativa, que resultou em uma descaracterização do principal mecanismo processual brasileiro. (BRASIL, 1973b). Assim é que, a elaboração do novo Código de Processo Civil brasileiro, através da recente aprovação da Lei Federal n. 13.105/2015, encontrou sua essência fundamental na necessidade de resistematização do principal instrumento processual brasileiro. Ressalte-se ainda o aumento dos poderes instrutórios e decisórios do julgador, como exemplo a própria concessão de tutelas de evidência de ofício, tanto nas mãos do magistrado de primeiro grau, quanto do relator do processo nos tribunais, o que parece ser o tônus da nova codificação brasileira, com amplo prestígio ao princípio da celeridade e o vínculo infraconstitucional à teoria instrumentalista do processo (BRASIL, 2015), objeto principal de estudo no Instituto Brasileiro de Direito Processual (INSTITUTO, 2015a).

Para a doutrina instrumentalista, "o conceito de jurisdição não seria jurídico, mas, político, já que ela é expressão do poder do Estado" (GONÇALVES, 2012, p. 157), fazendo com que a atividade do juiz seja influenciada por seus próprios princípios ideológicos, construída unilateralmente por sua clarividência, em uma atividade solitária e solipsista, o que não é compatível com a noção democrática de processo. Ou seja, ao tratar o processo como um instrumento de busca pela "paz social" e "pela justiça”, admite-se que o magistrado se torne a figura suprema da relação processual e atue de forma discricionária e arbitrária, buscando aplicar sua própria e subjetiva noção de "justiça”, assim desconsiderando a atuação das partes/participação popular, o que não se mostra consentâneo com a atual conjuntura constitucional do processo. 
Assim, referida doutrina deve ser abandonada, uma vez que, no contexto democrático, não se pode "reduzir o processo a uma relação jurídica vista como um mecanismo no qual o Estado-juiz implementa sua posição de superioridade de modo que o debate processual é relegado a segundo plano" (NUNES, 2011, p. 49).

Como superação da mencionada teoria, na tentativa de ampliar a participação das partes no processo jurisdicional, surge a teoria estruturalista ${ }^{9}$ de Elio Fazzalari, segundo o qual o processo seria o procedimento em contraditório, cuidando Fazzalari de diferenciar procedimento de processo e de elevar o contraditório à condição de pressuposto essencial para a existência de processo. (FAZZALARI, 2006).

Dessarte, esclarece Fazzalari:

Existe, em resumo, o 'processo', quando em uma ou mais fases do iter de formação de um ato é contemplada a participação não só - e obviamente - do seu autor, mas também dos destinatários dos seus efeitos, em contraditório, de modo que eles possam desenvolver atividades que o autor do ato deve determinar, e cujos resultados ele pode desatender, mas não ignorar. (FAZZALARI, 2006, p. 120).

A teoria de Fazzalari é de grande relevância para a compreensão do processo democrático, uma vez que inclui o contraditório como parte do conceito de processo, concluindo que náo há processo, mas tão somente procedimento, quando ausente o contraditório. A relevância dos estudos de Fazzalari não está somente na diferenciação entre processo em procedimento, mas também na inclusão da participação das partes como elemento essencial para que haja processo.

Percebe-se que, assim, iniciam-se os estudos do Direito Processual a partir de uma perspectiva democrática, fazendo com que a atividade jurisdicional deixasse de ser controlada pelo julgador, incluindo, agora, a participação e fiscalização dos interessados.

A atividade jurisdicional não pode, portanto, ser reduzia a mera "vontade do intérprete (julgar conforme sua consciência), como se a realidade fosse reduzida à sua representação subjetiva" , tendo em vista que a função do julgador se limita a ser "o aplicador da lei como intérprete das articulaçóes lógico-jurídicas produzidas pelas partes construtoras da estrutura procedimental" (LEAL, 2010, p. 63).

Complementando a teoria de Fazzalari, a teoria constitucionalista do processo, marco teórico do presente trabalho, não afasta a alegação de ser o processo um procedimento em contraditório, mas acrescenta que o processo seria também uma garantia de exercício dos direitos fundamentais, o que lhe concede uma perspectiva constitucional.

9 Ronaldo Brêtas de Carvalho Dias e Carlos Henrique Soares afirmam que a teoria elaborada por Fazzalari é denominada estruturalista, porque trata o processo como "procedimento que se desenvolve dentro da estrutura dialética e constitucionalizada do contraditório” (SOARES; BRÊTAS, 2011, p. 103). 
É o que considera Ronaldo Brêtas de Carvalho Dias:

[...] a teoria estruturalista de Fazzalari carece de alguma complementação pelos elementos que compóe a teoria constitucionalista, porque a inserçáo do contraditório no rol das garantias constitucionais decorre da exigência lógica e democrática da co-participação paritária das partes, no procedimento formativo da decisão jurisdicional que postulam no processo, razão pela qual conectada está à garantia também constitucional da fundamentação das decisóes jurisdicionais centrada na reserva legal, condição de efetividade e legitimidade democrática da atividade jurisdicional constitucionalizada. (BRÊTAS, 2010, p. 91).

A teoria constitucionalista do processo tem por base o estudo dialógico participativo, principal foco de pesquisa na Escola Mineira de Processo, conforme destaque no Instituto Mineiro de Direito Processual (INSTITUTO, 2015b). Para tanto, comentário de Dierle Nunes:

A percepção democrática do direito rechaça a possibilidade de um sujeito solitário captar a percepção do bem viver em sociedade altamente plurais e complexas e, no âmbito jurídico, a aplicação do direito e/ou o proferimento de provimentos, fazendo-se necessária a percepção de uma procedimentalidade na qual todos os interessados possam influenciar na formação das decisôes. Assim, toda decisão deve ser resultado de um fluxo discursivo balizado por um procedimento embasado nos princípios fundamentais (processo) que permita uma formaçáo processual de todo exercício do poder. (NUNES, 2011, p. 203).

A origem dos estudos acerca do processo em conjunto com o texto constitucional remonta ao mexicano Hector Fix-Zamudio ${ }^{10}$ e ao uruguaio Eduardo Couture ${ }^{11}$.

Em homenagem a memória de Eduardo J. Couture, o Instituto Iberoamericano de Direito Processual foi fundado em Montevidéu, nas Primeiras Jornadas Latino-Americanas de Direito Processual, realizadas em 1957, representando importante associação civil nos estudos da democratização do Direito Processual. (INSTITUTO, 2015c).

10 Fix-Zamudio, em sua obra "Constituición y Proceso Civil en Latinoamérica", de 1974, analisou a relevância que as garantias fundamentais passaram a ter nos estudos de direito processual, concluindo que, diante da existência de numerosas disposiçóes constitucionais acerca dos direitos das partes no processo civil, torna-se impossível desvincular qualquer legislaçáo processual de tais direitos fundamentais. (FIXZAMUDIO, 1974).

11 Apesar de verificar que Eduardo Couture ainda considera o processo como um instrumento da jurisdição, seguindo a orientação da Teoria do Processo como Relação Jurídica de Büllow, é possível constatar em seus estudos um esboço de um direito processual constitucional, a partir da ideia de que o processo deve ser estruturado por meio de um método dialético, permitindo que as partes e o juiz realizem o debate, tendo esclarecido Couture que a atividade jurisdicional se "serve da dialética porque o princípio da contradição é o que permite, por confrontaçáo dos opostos, chegar à verdade” (COUTURE, 2008, p. 44). 
Diante dos avançados estudos do Processo constitucionalizado, José Alfredo de Oliveira Baracho afirma que "o direito processual tem linhagem constitucional, circunstância que dá maior significação à proteção efetiva dos direitos processuais, em todas as instâncias" (BARACHO, 2006, p. 14), ainda acrescentando que "o processo constitucional visa tutelar o princípio da supremacia constitucional, protegendo os direitos fundamentais" (BARACHO, 2006, p. 95).

Desse modo, tem-se que as normas processuais devem observar a supremacia da Constituição $^{12}$, uma vez que o processo é considerado uma importante garantia constitucional. Por isso, as normas processuais, como já demonstrado, surgem consolidadas nos textos das Constituiçôes do moderno Estado Democrático de Direito, "sufragando os direitos das pessoas obterem a função jurisdicional do Estado, segundo a metodologia normativa do processo constitucional” (BRÊTAS, 2010, p. 92).

Conforme informa Baracho, "o modelo constitucional do processo civil assenta-se no entendimento de que as normas e os princípios constitucionais resguardam o exercício da função jurisdicional" (BARACHO, 2006, p. 15), o que leva ao entendimento de que a jurisdição é direito fundamental, e que, por consequência, seria inviável compreender o processo como mero instrumento de sua realização, devendo ser compreendido como forma de garantia não só deste, mas de todos os direitos fundamentais positivados pelo texto constitucional.

Em consonância com tais apontamentos, André Del Negri esclarece que "são as partes processuais que orientam a fundamentação da decisão (relação jurídica entre normas), e não mais uma vontade emanada da esfera solitária de convicção do juiz" (DEL NEGRI, 2011, p. 87). Assim, percebe-se a clara vinculação do princípio do contraditório ao princípio da fundamentação das decisóes, como informam Débora Fioratto e Ronaldo Brêtas:

No Estado Democrático de Direito, o contraditório deve ser compreendido como princípio de influência e de não surpresa, tornando-se base para o princípio da fundamentação da decisão e para o exercício do controle da argumentação utilizada pelo juiz. Se houver a restrição ou a supressão da garantia constitucional do contraditório, certamente, haverá a violação da garantia constitucional da fundamentação das decisōes. Ao passo que se o princípio da fundamentação das decisóes for respeitado, o contraditório também foi respeitado no trâmite processual. (FIORATTO; BRÊTAS, 2010, p. 132).

12 Segundo José Afonso da Silva, Supremacia da Constituição significa que esta se encontra no vértice do sistema jurídico conferindo validade a todos os atos do Estado realizados conforme reconhecido no texto constitucional, na proporção em que os poderes estatais forem distribuídos (SILVA, 2007, p. 45). Afirma também José Cirilo Vargas que a "constituição é que forma o arcabouço jurídico-político de uma Nação", traçando "os pressupostos de todos os setores da ordem jurídica", inclusive do Processo. (VARGAS, 1992, p. 57). 
Assim, a inclusão no texto constitucional brasileiro, em 1988, de diversas garantias processuais, que pretendem a efetividade dos direitos fundamentais, aproxima o processo da Constituiçãao, tornando, ainda, o texto constitucional indispensável para o devido processo, situação esta que torna clara a denominação "modelo constitucional de processo". (BARACHO, 1984).

\section{A Construção do Estado Democrático de Direito Ibero-Americano por Meio do Processo Constitucional}

Diante da análise realizada nos tópicos anteriores, percebeu-se que, mediante a inclusão das garantias processuais nos textos constitucionais, alterou-se a compreensão do processo e da atividade jurisdicional, não mais existindo uma atividade solitária e autoritária do julgador, o qual deve garantir que as partes exerçam o contraditório, em simétrica paridade, de forma a construir conjuntamente o provimento jurisdicional.

No processo democrático, não se trata o julgador como um ator criativo, nem, por outro lado, como um burocrata, mas sim como indicado pelo Estado para exercer a função jurisdicional, preservando o exercício do contraditório pelas partes, para que estas também construam o provimento jurisdicional, de forma participada.

Apesar das previsóes contidas no texto constitucional, é certo que a instauração da democracia não é automática, dependendo da verdadeira inclusão dos interessados na participação da construção das decisóes estatais.

Outro ponto de destaque e essencial acréscimo para o entendimento do tema foi a contribuição de Jürgen Habermas na teoria do discurso ao dar visibilidade as minorias e ao mencionar a necessidade do processo legislativo de justificação das normas jurídicas, em que os sujeitos são ao mesmo tempo autores e destinatários das normas, como compreensão do Estado Democrático de Direito. (HABERMAS, 2003, p. 191). ${ }^{13}$

Ressalta-se, também, a relação entre autonomia pública e privada, enumerada por Jürgen Habermas para o processo de legiferação como respeito aos direitos fundamentais

13 A importância da Teoria do Discurso, para Rosemiro Pereira Leal, está no fato de que "a desmitificação do Judiciário no Estado democrático de direito náo se faz pela melhoria do nível técnico dos juízes e por juramentos mais fervorosos de obediência à lei e à prática de justiça, mas por sua inclusáo e submissão, como instância pública, ao espaço jurídico-processual de comprometimento institucional com o direito democrático que pressupóe a compreensão da teoria do discurso como base de validade da construção jurisprudencial (jurisdiscente)." (LEAL, 2002, p. 142), sendo que quem "administra" é o processo constitucional, reservando ao magistrado o papel de partícipe (diretor dialogador do processo) da construçáo da decisão jurisdicional. Na modernidade o magistrado não é a "boca" da lei, e sim o seu hermeneuta, desde que entendido o referencial lógico que é o Estado Democrático de Direito, bem como a aplicação do processo constitucional. Há que se ter em mente que a lei, por si só, não dita o direito, mas o faz pela teoria do discurso. (Cf. LEAL, 2010, p. 269). 
em geral, as decisões da maioria são limitadas por meio de uma proteção dos direitos fundamentais das minorias; pois os cidadãos, no exercício de sua autonomia política, não podem ir contra o sistema de direitos que constitui esta mesma autonomia. [...] O processo democrático que institucionaliza as formas comunicativas necessárias para uma formação política racional da vontade tem que satisfazer simultaneamente a diferentes condições da comunicação. (HABERMAS, 2003, p. 224-225).

Importante, nesse ponto, a ressalva de Eugênio Pacelli de Oliveira à teoria de Habermas, ao apontar impasses quando afirma que a grande maioria dos membros da comunidade não dispóe de recursos (meios instrumentais e materiais) para participar, e conseqüentemente contribuir, na formação do consenso e do seu próprio destino (construção das decisóes políticas e jurídicas), permanecendo como um projeto de coexistência desejada, até que ocorra a igualdade material ("não só na lei, mas na sua capacidade de exercício da liberdade") com transformação social e inclusão do indivíduo na comunidade jurídica. (OLIVEIRA, 2012, p. 18-19).

Pacelli, no entanto, concorda com a busca sistemática dos melhores argumentos, defendida por Habermas, pelo que se torna alternativa bastante proveitosa à atualização do Direito positivado, a falibilidade das normas jurídicas, evitando-se que a sociedade e o próprio Direito se tornem reféns da legislação que, "via de regra, o tempo cuida de demonstrar a superação de graus mínimos de reprovação social”. (OLIVEIRA, 2012, p. 18-19).

Vale colacionar também a visão crítica de Karl Popper sobre a falibilidade, pelo que

[...] por falibilismo entende aqui a opiniáo, ou a aceitaçáo do fato, de que podemos errar e de que a busca da certeza (ou mesmo a busca de alta probabilidade) é uma busca errônea. Mas isto não implica que a busca de verdade seja errônea. Ao contrário, a idéia de erro implica a da verdade como padrão que podemos não atingir. Implica que, embora possamos buscar a verdade e até mesmo encontrar a verdade (como creio que fazemos em muitíssimos casos), nunca podemos estar inteiramente certos de que encontramos [...] Mas o falibilismo não precisa, de modo algum, dar origem a quaisquer conclusóes céticas ou relativistas. Torna-se-á isto claro se considerarmos que todos os exemplos históricos conhecidos de falibilidade humana - incluindo todos os exemplos conhecidos de erros judiciários - são exemplos do avanço de nosso conhecimento. [...] a crítica, parece, é o único modo que temos de identificar nossos erros e de aprender com eles de maneira sistemática. (POPPER, 1987, p. 395-396).

Rosemiro Pereira Leal, adotando o falibilismo de Popper, acrescenta à Teoria do Discurso o fato de que

a ligação entre poder e decisão por seqüelas históricas consolidou, na modernidade, uma compreensão distorcida do julgar em que vontade 
e inteligência freqüentam, por ensino de muitos, a mesma sede, que é a mente predestinada do sábio-julgador. [...] A processualidade jurídica institucionalizadora e recriativa do acervo normativo do Estado democrático é que provocaria o salto para a pós-modernidade jurídica que requer não somente características de positividade (legalidade formal da modernidade), mas agregaria conteúdos jurídicos de testificação discursiva [Popper] propiciadores de processual e incessante fiscalidade irrestrita, abstrata e concreta das bases de produçáo, legiferação e cumprimento (aplicação) do direito, que só assim se mostraria realizador do princípio da democracia. (LEAL, 2002, p. 27).

No presente ponto, cabe destacar a correlação da Teoria do Discurso (princípio do discurso) com o Estado Democrático de Direito (princípio da democracia) vez que ocorre, conforme observaçóes de Rosemiro Pereira Leal, pelo processo, aqui entendido como processo constitucional. (LEAL, 2002, p. 16). ${ }^{14}$

Nesta estrutura técnica, por meio do direito ao voto, permite-se que a democracia se torne a vontade da maioria. Mas, conforme esclarece Simone Goyard-Fabre, "as virtudes da democracia são também sua fraqueza" (GOYARD-FABRE, 2003, p. 342). Isso porque, diante da diversidade de individualidades, a escolha da maioria pode ocasionar uma exclusão da minoria. Assim, a democracia não permitiria a inclusão de todos os interessados.

Para que seja possível essa inclusão, necessita-se da democratização do processo jurisdicional ibero-americano, o que somente é possível a partir da compreensão do processo a partir da Teoria Constitucionalista.

Acerca da inclusão dos interessados, Fix-Zamudio aponta como essencial o princípio da ampla defesa e afirma ${ }^{15}$ :

Este princípio fundamental de qualquer regime democrático e que, em termos gerais, implica igualdade de oportunidades, transcendeu a esfera processual em várias direções, e uma das mais importantes é o chamado caráter dialético do processo ou "contraditório", o qual significa que qualquer procedimento jurisdicional requer a intervenção equilibrada

14 Com o esclarecimento: "A aplicação das normas jurídicas ao caso concreto depende da co-relaçáo do discurso de justificação e do discurso de aplicação, através da argumentação jurídica e racional (fundada só em argumentos de direito - e não na moral, religiáo, e outra ideologias) realizada pelo consenso das partes, e não da "cabeça" do magistrado. Baseadas na lógica discursiva de Popper e reteorizaçôes de Habermas". (LEAL, 2002, p. 16).

15 No original: "Este princípio fundamental de todo regímen democrático y que en términos generales implica la igualdad de oportunidades há transcendido el ambito procesal em varias direcciones, y uma de las mas importantes es el llamado caracter dialético del proceso o "contraditório", el cual significa que todo procedimiento jurisdicional requiere de la intervención equilibrada de las partes esenciales que poseen intereses contrapostos, y se condensa el la frase: audiatur et altera pars". 
das partes essenciais que apresentem interesses contrapostos, e condensa a frase audiatur et altera pars. (FIX-ZAMUDIO, 1974, p. 63-64).

É o que também esclarecem Dierle Nunes e Alexandre Bahia:

A Democracia trabalha com a ideia de maiorias: temas são apresentados e a maioria dos votantes elege a opçáo vencedora. A Constituição, por outro lado, funciona como repositório de direitos fundamentais de que minorias podem se valer para se defender contra pretensôes da maioria. (NUNES; BAHIA, 2010, p. 63).

A atividade jurisdicional exercida por meio do processo constitucional deve ser considerada como a função do Estado destinada à repressão de desrespeitos à ordem democrático-legal, sendo "capaz de concretizar condiçóes de desenvolvimento humano através da tutela de direitos fundamentais" (LIMA, 2009, p. 19). Assim, permite-se que todo e qualquer cidadão, e não somente a maioria, sejam detentores dos direitos fundamentais constitucionalmente previstos.

José Alfredo de Oliveira Baracho afirma ainda sobre processo constitucional:

O processo constitucional não é apenas um direito instrumental, mas uma metodologia de garantia dos direitos fundamentais. Suas instituiçôes estruturais (jurisdição, ação e processo) remetem-nos à efetivação dos direitos essenciais. [...] O processo constitucional apresenta condições processuais específicas, que decorrem da legitimação e do conceito de parte. Sendo que a sua instalação depende da ocorrência dos pressupostos processuais, para a correta integração da Ação, da Legitimação e do Processo. As garantias e os processos constitucionais corporificam as garantias individuais e as garantias constitucionais. Encontramos no inglês a palavra warranty, que quer dizer assegurar, proteger, salvaguardar (to warrant). [...] A ação processual é uma garantia básica, em qualquer de suas modalidades, como ocorre com o processo constitucional. Garantese não somente o direito de peticionar e de ser ouvido, mas o direito ao processo. O devido processo ou o processo justo, o direito de defesa e a assistência legal, o processo como manifestação de igualdade e equilíbrio são aspectos essenciais do desenvolvimento desse tema. O processo constitucional, de diversas formas, destina-se a respaldar as garantias fundamentais, possibilitando a efetiva tutela, proteção e fomento delas. [...] As garantias individuais, coletivas e processuais tornam possível o exercício da cidadania plena, através do processo constitucional. As garantias individuais e as sociais são consagraçóes que possibilitam o exercício da pluralidade dos direitos. A necessidade efetiva de dar suporte às garantias leva às indagações sobre sua codificação. [...] Todos esses temas são necessários à elaboração definitiva da Teoria geral do processo constitucional. (BARACHO, 2006, p. 46-49). 
Por sua vez, Fernando Gonzaga Jayme bem destaca o processo constitucional como garantia para a efetivaçáo dos direitos fundamentais e, dentre estes, o direito à uma decisão por um devido processo constitucional, pela função jurisdicional ou pela função administrativa. (JAYME, 2000, p. 55).

E, complementa o mesmo autor, afirmando que:

a constitucionalizaçáo dos direitos fundamentais coloca o Processo Constitucional como instrumento essencial à dignidade humana, já que os textos constitucionais não mais disciplinam apenas a organizaçáo do Estado em si mesmo, mas também as relaçóes desse com os cidadãos. $\mathrm{O}$ leque dos direitos constitucionalizados foi ampliado consideravelmente ao serem classificados em direitos fundamentais sociais, econômicos e políticos, demandando efetiva e contínua garantia através do Processo Constitucional. (JAYME, 2000, p. 58).

Assim, esclarece Rosemiro Pereira Leal:

O espaço-político (isegoria) de criação do direito só será continente democrático se já assegurados os conteúdos processuais dialógicos da isonomia - que são a isotopia, isomenia e isocrítica - em que haja, portanto, em sua base decisória, igualdade de todos perante a lei (isotopia), igualdade de todos de interpretar a lei (isomenia) e igualdade de todos de fazer, alterar ou substituir a lei (isocrítica). (LEAL, 2010, p. 61).

Segundo Dierle José Coelho Nunes, o "processo começa a ser percebido como um instituto fomentador do jogo democrático" (NUNES, 2011, p. 40). E, em decorrência, torna-se também uma garantia ao exercício dos direitos fundamentais. Ou seja, o processo deve ser compreendido como forma de garantia de direitos de participação e condiçóes procedimentais que possibilitam a geração legítima do provimento jurisdicional.

A concretização da democracia exige não só que os interessados tenham o direito de se manifestar, mas sim que essa manifestação seja considerada pelo ente estatal, seja capaz de construir o provimento final com técnica e que seja eficaz para permitir o amplo exercício de todos os direitos fundamentais previstos constitucionalmente.

Tem-se a técnica como o conjunto de procedimentos, numa relação meio-fim, na busca de resultados úteis. Para Aroldo Plínio Gonçalves, trata-se do "conjunto de meios adequados para a consecução dos resultados desejados, de procedimentos idôneos para a realização de finalidades”. (GONÇALVES, 2012, p. 23).

Para Eduardo García Máynez toda técnica tem que estar fundamentada na ciência, caso contrário torna-se incapaz de cumprir o seu destino. (MÁYNEZ, 1975, p. 317).

Para tanto, tem-se a ciência como atividade de esclarecimentos e fundamentação do conhecimento ou o próprio conjunto de conhecimentos esclarecidos e fundamentados. 
A norma é cânone de valorização de conduta, em que o ordenamento jurídico é o complexo de normas, de faculdades, de poderes, de deveres, o complexo de licitudes. $\mathrm{O}$ ilícito nele comparece, mas como a conduta que consiste na inobservância do dever.

Nesse ponto, é de se ressaltar o paradigma constitucional do processo, uma vez que influencia como também orienta a técnica de elaboração e de aplicação da norma processual. Frise-se que intimamente relacionado ao princípio do devido processo constitucional, que por sua vez é aglutinador de direitos e garantias fundamentais explicita e implicitamente elencados na Constituiçáo, quais sejam: direito de acesso ao processo (administrativo ou judicial), com observância do tempo útil e razoável; garantia do contraditório; garantia da ampla e irrestrita defesa, por meio de advogado ou defensor público; garantia ao juízo natural; garantia à fundamentaçáo das decisóes; e, garantia da utilidade e razoabilidade do processo, com eliminação das etapas mortas do processo. (BRÊTAS, 2006b, p. 229). ${ }^{16}$

Ressalta-se que o desrespeito da técnica de elaboração e de aplicação da norma processual ao paradigma constitucional do processo só não é mais grave ao Estado Democrático de Direito, se o julgador utilizar da técnica de interpretação da norma observando o princípio do devido processo constitucional adequado ao caso.

Nesse sentido, o desafio lançado por Rosemiro Pereira Leal:

uma Teoria da Constituição, que se proponha como disciplina científica, há de explicar qual paradigma de Estado está encaminhando à compreensão de seus conteúdos programáticos. Não há uma teoria de uma constituição universal separada das teorias fundantes das instituiçóes que compóem sua enunciaçáo jurídica. Esse aspecto é relevante à elucidação das bases de normação jurídica instituintes das intervenções das Administraçôes-Governativas (ESTADOS) nos espaços natural e virtual de modo a não tolher pelo panóptico o ontóptico em seu "deixar-fazer-aparecer” por direitos fundamentais de proceder-ser-ter-haver nos espaços-tempos de compartilhamento lingüístico. A permitir que o Estado seja o mesmo em sua ortodoxia opressiva e todista, a açambarcar todos os níveis de liberdade e privacidade em nome de uma segurança pública, a CONSTITUIÇÃO em que esse ESTADO estivesse inserido não teria sido construída a partir do espaço-tempo-processualizado, não se revestindo de qualificação democrático- econômica na concepção pósmoderna de DEMOCRACIA aos moldes teóricos aqui desenvolvidos. (LEAL, 2012, p. 16).

Assim, busca-se uma verdadeira igualdade entre todos os cidadãos e não somente a prevalência da vontade da maioria, ao contrário do que se costuma dizer a respeito da democracia.

16 O autor destaca a "técnica" como conjunto de procedimentos logrados para atingir determinadas finalidades, observadas as garantias e direitos fundamentais constitucionais. (BRÊTAS, 2006, p. 244). 
Fix-Zamudio ainda afirma que essa almejada igualdade pode ser concebida de formas diversas, de acordo com o momento jurídico-político. E destaca que, após a segunda guerra, predomina uma concepçáo socializadora do direito, cuidando os ordenamentos jurídicos latino-americanos de garantir uma igualdade real entre as partes e não meramente formal como ocorre em um regime individualista e liberal (FIX-ZAMUDIO, 1974, p. 64).

Desse modo, percebe-se que o processo jurisdicional, se analisado nessa perspectiva constitucional-democrática, é mecanismo essencial para a concretização do Estado Democrático de Direito, uma vez que permite a inclusão daqueles que não conseguem exercer sua influência no poder estatal a partir da manifestaçáo da maioria. $\mathrm{O}$ processo constitucionalizado, portanto, é capaz de resolver os problemas de individualidade que prejudicam a democracia nos países ibero-americanos.

\section{Conclusões}

Diante das consideraçóes tecidas no texto, é possível perceber que a instauração do Estado Democrático de Direito ocasionou a mudança da matriz disciplinar que rege a atuação estatal, incluindo a atividade jurisdicional.

Desse modo, a Jurisdição passa a ser um direito fundamental, cujo exercício deve ser democratizado pelos países ibero-americanos, o que somente é possível por meio da adequada compreensão do princípio do contraditório, utilizando como marco teórico a Teoria Constitucionalista do Processo. Ao compreender o contraditório somente como um direito de manifestaçáo das partes interessadas, não se permite a devida democratização do processo e da atividade jurisdicional, tendo em vista que não afasta a discricionariedade e arbitrariedade do julgador e nem mesmo inclui como motivação dos atos jurisdicionais os argumentos apresentados pelas partes.

O Processo deve servir como uma instituição de cidadania democrática, inconcebível a formulação de decisões sem observância da técnica normativa estrutural, pautada principalmente no paradigma constitucional do processo, em que devem ser observadas as razóes de justificação deduzidas pelas partes, no procedimento em contraditório, pela simétrica paridade, em torno das questóes de fato e de direito processual ou material discutidas nos autos.

A concretização da democracia exige não só que os interessados tenham o direito de se manifestar, mas sim que essa manifestação seja considerada pelo ente estatal, seja capaz de construir o provimento final. Assim, nos atos jurisdicionais, somente é possível falar em concretização da democracia se os provimentos forem proferidos mediante a análise de todos os argumentos apresentados pelas partes interessadas, sendo vedada a decisão em dissonância com a manifestação de qualquer das partes ou que represente, em verdade, a opiniáo pessoal do julgador. 


\section{Referências}

ANDORRA, Constituición del Principado de Andorra. Disponível em: <http://www.consellgeneral.ad/fitxers/documents/constitucio/const-cast>. Acesso em: 17 maio 2015.

BARACHO, José Alfredo de Oliveira. Processo constitucional. Rio de Janeiro: Forense, 1984.

BARACHO, José Alfredo de Oliveira Baracho. Direito Processual Constitucional: Aspectos Contemporâneos. Belo Horizonte: Fórum, 2006.

BRASIL, Constituição de 1988. Constituiçáo da República Federativa do Brasil de 1988. Disponível em: <http://www.planalto.gov.br/ccivil_03/constituicao/constituicao. $\mathrm{htm}>$. Acesso em: 17 maio 2015.

BRASIL, Lei n. 5.869, de 11 de janeiro de 1973. Institui o Código de Processo Civil. Disponível em: <http://www.planalto.gov.br/ccivil_03/leis/15869compilada.htm>. Acesso em: 17 maio 2015.

BRASIL, Lei n. 13.105, de 16 de março de 2015. Código de Processo Civil. Disponível em: <http://www.planalto.gov.br/ccivil_03/_Ato2015-2018/2015/Lei/L13105.htm\#art1046>. Acesso em: 17 maio 2015.

BRÊTAS, Ronaldo de Carvalho Dias. Direito à Jurisdição Eficiente e Garantia da Razoável Duração do Processo no Estado Democrático de Direto. In: GALUPPO, Marcelo Campos (Org.). O Brasil que Queremos: Reflexões sobre o Estado Democrático de Direito. Belo Horizonte: PUC Minas, 2006.

BRÊTAS, Ronaldo de Carvalho Dias. As reformas do código de processo civil e o processo constitucional. In: BRÊTAS, Ronaldo de Carvalho Dias; NEPOMUCENO, Luciana Diniz (Coords.). Processo civil reformado. Belo Horizonte: Del Rey, 2006.

BRÊTAS, Ronaldo de Carvalho Dias. Exame Técnico e Sistemático do Código de Processo Civil Reformado. In: BRÊTAS, Ronaldo de Carvalho Dias; NEPOMUCENO, Luciana (Org.). Processo civil reformado. 2. ed. Belo Horizonte: Del Rey, 2009.

BRÊTAS, Ronaldo de Carvalho Dias. Processo Constitucional e Estado Democrático de Direito. Belo Horizonte: Del Rey, 2010.

CHILE, Constituición Política de la República. Disponível em: <http://www.oas.org/dil/ esp/constitucion_chile.pdf>. Acesso em: 17 maio 2015.

COLÔMBIA, Constituición Politica de Colômbia. Disponível em: < http://wsp.presidencia.gov.co/Normativa/Documents/ConstitucionPoliticaColombia_20100810.pdf>. Acesso: 17 maio 2015.

COUTURE, Eduardo. Introdução ao Estudo do Processo Civil: Discursos, Ensaios e Conferências. Trad. Hiltomar Martins Oliveira. Belo Horizonte: Líder, 2008. 
DEL NEGRI, André . Processo Constitucional e decisão interna corporis. Belo Horizonte: Fórum, 2011.

DINAMARCO, Cândido Rangel. Instituiçôes de Direito Processual Civil. São Paulo: Malheiros, 2004. v. 1.

ESPANHA, La Constitución Española de 1918. Biblioteca Virtual Miguel de Cervantes. Disponível em: <http:/www.cervantesvirtual.com/portales/constitucion_1812/>. Acesso em: 17 maio 2015.

ESPANHA, Constituição de 1978. Disponível em: < http://www.tribunalconstitucional. es/es/constitucion/Paginas/ConstitucionIngles.aspx> Acesso em: 17 maio 2015.

FAZZALARI, Elio. Instituiçóes de Direito Processual. Trad. Elaine Nassif. Campinas: Bookseller, 2006.

FIORATTO, Débora Carvalho; BRÊTAS, Ronaldo de Carvalho Dias. A Conexão entre os Princípios do Contraditório e da Fundamentação das Decisóes no Estado Democrático de Direito. Revista Eletrônica do Curso de Direito - PUC Minas Serro. V. 01, 2010 .

FIX-ZAMUDIO, Hector. Constituición y Proceso Civil en Latinoamérica. Ciudad de México: Instituto de Investigaciones Juridicas, 1974.

FONSECA, Rodrigo Rigamonte. Isonomia e Contraditório na Teoria do Processo. In: LEAL, Rosemiro Pereira (Coord.) Estudos Continuados de Teoria do Processo. Porto Alegre: Síntese, 2000. v. 1

GONÇALVES, Aroldo Plínio. Técnica processual e teoria do processo. 2. ed. Belo Horizonte: Del Rey, 2012.

GOYARD-FABRE, Simone. O que é democracia?. Trad. de Cláudia Berliner. São Paulo: Martins Fontes, 2003.

GRESTA, Roberta Maia. Introdução aos fundamentos da processualidade democrática. Rio de Janeiro: Lumen Iuris, 2014.

HABERMAS, Jürgen. Direito e democracia: entre facticidade e validade. 2. ed. Trad. Flávio Beno Siebeneichler. Rio de Janeiro: Tempo Brasileiro, 2003. v. I.

INSTITUTO Brasileiro de Direito Processual. IBDP. Disponível em: <http://www.direitoprocessual.org.br/>. Acesso em: 17 maio 2015.

INSTITUTO Mineiro de Direito Processual. IMDP. Disponível em: <www.imdp.com. br/home>. Acesso em: 17 maio 2015.

INSTITUTO Iberoamericano de Direito Processual. IIDP. Disponível em: <http://iibdp. org/index.php/pt/espanol.html>. Acesso em: 17 maio 2015. 
ITÁLIA, Constituição de 1947. Disponível em: <http:/www.quirinale.it/qrnw/statico/ costituzione/pdf/Costituzione.pdf>. Acesso em: 17 maio 2015.

JAYME, Fernando Gonzaga. Tribunal constitucional: exigência democrática. Belo Horizonte: Del Rey, 2000.

LEAL, Rosemiro Pereira. Teoria processual da decisão jurídica. São Paulo: Landy, 2002.

LEAL, Rosemiro Pereira. Teoria Geral do Processo: primeiros estudos. 9. ed. Rio de Janeiro: Forense, 2010.

LEAL, Rosemiro Pereira. O paradigma processual ante as sequelas míticas do poder constituinte originário. In: CASTRO, João Antônio Lima; FREITAS, Sérgio Henriques Zandona (Coords.). Direito processual. Belo Horizonte: Instituto de Educação Continuada da Pontifícia Universidade Católica de Minas Gerais (IEC-PUC-Minas), 2012.

LEAL, Rosemiro Pereira. A Teoria Neoinstitucionalista do Processo: Uma Trajetória Conjectural. Belo Horizonte: Arraes, 2013.

LIMA, Newton de Oliveira. Jurisdição Constitucional e Construção de Direitos Fundamentais no Brasil e nos Estados Unidos. São Paulo: MP, 2009.

LOURENÇO, Haroldo. Manual de Direito Processual Civil. Rio de Janeiro: Forense, 2013.

MADEIRA, Dhenis Cruz. Processo de Conhecimento e Cognição. Curitiba: Juruá, 2009.

MÁYNEZ, Eduardo García. Introduccion al estúdio del derecho. 25. ed. Ciudad de México: Porrua, 1975.

NUNES, Dierle; BAHIA, Alexandre. Processo, Jurisdição e Processualismo Constitucional Democrático na América Latina. Revista Brasileira de Estudos Políticos, Belo Horizonte, n. 101, p. 61-96, jul./dez. 2010.

NUNES, Dierle José Coelho. Processo Jurisdicional Democrático. Curitiba: Juruá, 2011.

NUNES, Dierle. Processualismo Constitucional Democrático e o Dimensionamento de Técnicas para a Litigiosidade Repetitiva: A Litigância de Interesse Público e as Tendências "não Compreendidas" de Padronização Decisória. Revista de Processo, Vol. 199 , setembro/2011.

OLIVEIRA, Eugênio Pacelli. Processo e hermenêutica na tutela penal dos direitos fundamentais. 3. ed. São Paulo: Atlas, 2012.

PERU, Constituición Politica Del Perú. Disponível em: <http://www4.congreso.gob.pe/ ntley/Imagenes/Constitu/Cons1993.pdf>. Acesso em: 17 maio 2015.

POPPER, Karl. A sociedade aberta e seus inimigos. Trad. Milton Amado. Belo Horizonte: Itatiaia Edusp, 1987, v. 2. 
PORTUGAL, Constituição de 1974. Disponível em: <http://www.parlamento.pt/Legislacao/Paginas/ConstituicaoRepublicaPortuguesa.aspx>. Acesso em: 17 maio 2015.

SILVA, José Afonso da. Curso de Direito Constitucional Positivo. São Paulo: Malheiros, 2007.

SOARES, Carlos Henrique; BRÊTAS, Ronaldo de Carvalho Dias. Manual Elementar de Processo Civil. Belo Horizonte: Del Rey, 2011.

STRECK, Lenio Luiz. Verdade e consenso: constituição, hermenêutica e teorias discursivas. Rio de Janeiro: Lumen Juris, 2006.

THEODORO JUNIOR, Humberto; NUNES, Dierle. Princípio do Contraditório: Tendência de Mudança da sua Aplicação. Revista da Faculdade de Direito do Sul de Minas, Pouso Alegre, vol. 28: jan./jun.2009.

VARGAS, José Cirilo. Processo Penal e Direitos Fundamentais. Belo Horizonte: Del Rey, 1992. 